\title{
Zera i bieguny transmitancji a częstotliwości antyrezonansowe i rezonansowe układów nośnych pojazdów
}

\begin{abstract}
W zastosowaniach praktycznych często pojawia się problem ograniczenia drgań urzqdzeń zamocowanych na elementach podatnych, przy założeniu, że układ $w$ stanie ustalonym poddany jest obciażeniom o określonej częstotliwości. Znaczy to, że na kierunku wybranej wspótrzędnej uogólnionej przemieszczenia winny być minimalne. Odpowiada to analitycznemu zadaniu wyznaczenia zer odpowiedniej transmitancji układu. Wymagane wartości zer transmitancji układu uzyskano poddajac układ modyfikacji przez zastosowanie pasywnych elementów sprężystych lub tlumieniowych.
\end{abstract}

\section{Wprowadzenie.}

Dynamika liniowego, stacjonarnego układu mechanicznego o wielu stopniach swobody oraz o wielu wejściach i wyjściach reprezentowana jest macierzą transmitancji operatorowych i widmowych. Elementy macierzy transmitancji sa w takim przypadku przyczynowymi funkcjami wymiernymi zmiennej zespolonej. Miejsca zerowe mianowników macierzy transmitancji nazwano biegunami a miejsca zerowe liczników elementów macierzy transmitancji zerami. O ile badanie i interpretacja biegunów transmitancji dla układów mechanicznych są znane, o tyle badanie i interpretacje zer transmitancji dla układów mechanicznych przedstawiono $\mathrm{w}$ literaturze stosunkowo niedawno [3], gdzie omówiono fizyczną interpretację zer transmitancji jako częstotliwości anty-rezonansowych, czyli częstotliwości wymuszenia typu harmonicznego, przy których odpowiedź układu przyjmuje wartości bliskie zeru.

W pracach [4, 5] przedstawiono strukturalny aspekt interpretacji zer transmitancji. Stwierdzono, że zera transmitancji można interpretować jako bieguny układu uzyskanego z układu podstawowego. Wymaga to wprowadzenia więzów w postaci unieruchomienia na kierunkach współrzędnych uogólnionych zgodnych z kierunkami wymuszenia i odpowiedzi w badanym układzie.

W zastosowaniach praktycznych często pojawia się problem ograniczenia drgań maszyn, silników czy innych urządzeń zamocowanych na elementach podatnych przy założeniu, że układ w stanie ustalonym poddany jest wymuszeniu o stałej częstotliwości.

W procesie projektowania celem jest określenie struktury układu i charakterystyk sztywnościowo-tłumieniowych elementów podparcia dla uzyskania minimum odpowiedzi na kierunku określonej współrzędnej uogólnionej przy zadanej eksploatacyjnej częstotliwości wymuszenia.

Celem artykułu jest badanie (na wybranym przykładzie) wpływu modyfikacji struktury układu poprzez wprowadzenie pasywnych elementów sprężystych (sprężyna śrubowa) lub tłumiących (tłumik wiskotyczny) na wartości biegunów i zer elementów macierzy transmitancji, a tym samym na wartości częstotliwości rezonansowych i antyrezonansowych.

2. Transmitancja jako formalizm modelowania procesów zachodzących w liniowych układach mechanicznych.

Równania ruchu dyskretnego, liniowego, stacjonarnego modelu układu mechanicznego o $n$ stopniach swobody, przedstawiono w postaci :

$$
\mathbf{M} \cdot \ddot{\mathbf{q}}+\mathbf{D} \cdot \dot{\mathbf{q}}+\mathbf{K} \cdot \mathbf{q}=\mathbf{B} \cdot \mathbf{f}
$$

a równanie wyjść jako:

$$
\mathbf{y}=\mathbf{C} \cdot \mathbf{q}
$$

gdzie:

$\mathbf{q}, \quad \dot{\mathbf{q}}, \quad \ddot{\mathbf{q}}$ - wektory współrzędnych, prędkości i przyspieszeń uogólnionych ( $\left.\mathbf{q} \in \mathfrak{R}^{n \times 1}\right)$,

f - wektor wymuszeń w postaci sił ( $\mathbf{f} \in \mathfrak{R}^{m \times 1}$ ),

$\mathbf{y}$ - wektor wielkości mierzonych w postaci przemieszczeń $\left(\mathbf{y} \in \mathfrak{R}^{p \times 1}\right)$,

M, D, K - macierze bezwładności, tłumienia i sztywności ( $\mathbf{M}, \mathbf{D}, \mathbf{K} \in \mathfrak{R}^{n \times n}$ ),

B- macierz wejść rzędu $m\left(\mathbf{B} \in \mathfrak{R}^{n \times m}\right)$, $\mathbf{C}$ - macierz wyjść rzędu $p\left(\mathbf{C} \in \mathfrak{R}^{p \times m}\right)$, przy czym macierze $\mathbf{M}, \mathbf{D}, \mathbf{K}$ spełniają warunki:

$\mathbf{M}=\mathbf{M}^{T}>0, \mathbf{D}=\mathbf{D}^{T} \geq 0, \mathbf{K}=\mathbf{K}^{T} \geq 0$

Po przeprowadzeniu transformacji Laplace'a, co zapisano zależnością

$$
[\mathbf{y}(s), \mathbf{f}(s)]=\int_{0}^{\infty}[\mathbf{y}(t), \mathbf{f}(t)] \cdot e^{-s t} d t
$$

oraz przyjęciu zerowych warunków początkowych $\dot{\mathbf{q}}(0)=\mathbf{q}(0)=\mathbf{0}$ uzyskano związek między transformatami wektora wyjścia i wektora wejścia w postaci:

$$
\mathbf{y}(s)=\mathbf{H}(s) \cdot \mathbf{f}(s)
$$

Transmitancję operatorową $\mathbf{H}(s)$ wyznaczono jako:

$$
\begin{gathered}
\mathbf{H}(s)=\mathbf{C} \cdot\left(\mathbf{K}+s \cdot \mathbf{D}+s^{2} \cdot \mathbf{M}\right)^{-1} \cdot \mathbf{B}= \\
\mathbf{C} \cdot \mathbf{Z}(s) \cdot \mathbf{B}
\end{gathered}
$$

gdzie $\mathbf{Z}(s)$ jest zespoloną podatnością dynamiczną układu.

\subsection{Zera i bieguny transmitancji.}

Transmitancja wyrażona za pomocą zależności (5) jest macierzą wymierną, przyczynową, której elementy $h_{i j}(s)$ są przyczynowymi funkcjami wymiernymi 


$$
h_{i j}(s)=\frac{a_{i j}(s)}{b_{i j}(s)}, i=1, \ldots, p, j=1, \ldots, m
$$

gdzie

$a_{i j}(s)$ - licznik $\mathrm{w}$ postaci wielomianu zmiennej operatorowej,

$b_{i j}(s)$ - mianownik w postaci wielomianu zmiennej operatorowej.

Każdą przyczynową macierz wymierną można przekształcić za pomocą macierzy unimodularnych do kanonicznej postaci McMillana $\mathbf{H}_{M}(s)$ [1].

$$
\mathbf{H}_{M}(s)=\left[\begin{array}{cc}
\operatorname{diag}\left[\frac{m_{1}(s)}{v_{1}(s)}, \ldots, \frac{m_{r}(s)}{v_{r}(s)}\right] & \mathbf{0} \\
\mathbf{0} & \mathbf{0}
\end{array}\right]
$$

gdzie $r$ jest rzędem macierzy, a wielomiany $m_{i}(s)_{\text {oraz }}$ $v_{i}(s)$ są względnie pierwsze oraz wielomiany $m_{i+1}(s)$ (odpowiednio $v_{i}(s)$ ) dzielą się bez reszty przez wielomiany $m_{i}(s)$ (odpowiednio $v_{i+1}(s)$ ).

Miejsca zerowe wielomianu w liczniku

$$
m(s)=m_{1}(s) \cdot \ldots \cdot m_{r}(s)
$$

nazywamy zerami $z_{j}$ (skończonymi) macierzy transmitancji (5). Wielomian $m(s)$ jest równy największemu wspólnemu dzielnikowi liczników wszystkich minorów stopnia $r$ macierzy transmitancji (5) sprowadzonych do wspólnego mianownika [2].

Miejsca zerowe wielomianu w mianowniku

$$
v(s)=v_{1}(s) \cdot \ldots \cdot v_{r}(s)
$$

nazywamy biegunami $p_{i}$ (skończonymi) macierzy transmitancji (5). Wielomian $v(s)$ jest równy najmniejszemu wspólnemu mianownikowi wszystkich niezerowych minorów wszystkich stopni macierzy transmitancji (5) [2].

Liczbę $S=z$ nazywamy zerem transmisyjnym macierzy $\mathbf{H}(s)$, jeżeli wektor odpowiedzi układu poddanego wymuszeniu o postaci

$$
\mathbf{f}(t)=\mathbf{k}(t) \cdot e^{z t}
$$

gdzie $\mathbf{k} \in \mathfrak{R}^{m \times 1}$

jest równy zeru dla $t>0$, czyli gdy równanie (2) przyjmie postać

$$
\mathbf{C} \cdot \mathbf{q}=\mathbf{0}
$$

Zatem znalezienie wartości zer transmisyjnych macierzy transmitancji jest istotne z praktycznego punktu widzenia, ponieważ umożliwia wyznaczenie wektora odpowiedzi o składowych równych 0 (zero), na wymuszenie charakteryzowane przez zera transmisyjne (10).

\subsection{Strukturalna i fizyczna interpretacja zer trans- misyjnych oraz biegunów}

W dalszych badaniach przyjęto macierze $\mathbf{C}$ oraz $\mathbf{B}$ jako macierze jednostkowe, przy czym $\mathbf{C}, \mathbf{B} \in \mathfrak{R}^{n \times n}$.

Transmitancja operatorowa układu przyjmie zatem postać:

$$
\mathbf{H}(s)=\mathbf{Z}(s)
$$

Elementy $h_{i j}(s)$ macierzy (12) spełniają zależność

$$
\left[h_{i j}(s)\right]=\frac{\hat{\mathbf{H}}(s)}{|\mathbf{H}(s)|}
$$

gdzie:

$\hat{\mathbf{H}}(s)$ - transponowana macierz dopełnień algebraicznych, której elementy mają postać $\hat{h}_{i j}(s)=(-1)^{i+j}\left|\mathbf{H}^{j i}(s)\right|$,

$|\mathbf{H}(s)|$ - wyznacznik macierzy transmitancji.

Podmacierze $\mathbf{H}^{j i}(s)$ uzyskano poprzez skreślenie $j$-tego rzędu oraz $i$-tej kolumny w macierzy transmitancji $\mathbf{H}(s)$. Bieguny macierzy transmitancji są pierwiastkami wielomianu $|\mathbf{H}(s)|=0$. Zera macierzy transmitancji wyznaczane są według zależności (7) oraz (8).

$\mathrm{W}$ badaniach przyjęto, że w układzie występuje jedno wejście w postaci siły przyłożonej na kierunku wybranej współrzędnej uogólnionej oraz jedno wyjście w postaci przemieszczenia mierzonego na kierunku wybranej współrzędnej uogólnionej.

Przy tych założeniach zera transmitancji są równoważne pierwiastkom wielomianów występujących w licznikach odpowiednich skalarnych funkcji $h_{i j}(s)$ macierzy $\mathbf{H}(s)$, a bieguny są pierwiastkami wielomianów występujących $\mathrm{w}$ mianownikach tych funkcji.

Przyjmując, że wymuszenie przyłożone jest na kierunku $p$-tej współrzędnej uogólnionej a pomiar odbywa się na kierunku $q$-tej współrzędnej uogólnionej, sprowadzono wyznaczenie zer transmitancji do znalezienia pierwiastków wielomianu $\hat{h}_{p q}(s)=0$. Wyznaczone wartości odpowiadają biegunom transmitancji $\mathbf{H}_{p q}(s)$ uzyskanej w wyniku skreślenia $p$-tego wiersza i $q$-tej kolumny w macierzy transmitancji $\mathbf{H}(s)$. Wyznaczanie zer macierzy transmitancji zastapiono zatem wyznaczaniem wartości własnych macierzy o postaci:

$$
\mathbf{H}_{p q}(s)=\left(\mathbf{K}_{p q}+s \cdot \mathbf{D}_{p q}+s^{2} \cdot \mathbf{M}_{p q}\right)^{-1}
$$

gdzie macierze $\mathbf{K}_{p q}, \quad \mathbf{D}_{p q}, \quad \mathbf{M}_{p q}$ utworzono przez skreślenie $\quad p$-tego wiersza i $q$-tej kolumny w macierzach, odpowiednio $\mathbf{K}, \mathbf{D}$ oraz $\mathbf{M}$.

Rozkład zer i biegunów na płaszczyźnie zespolonej umożliwia ocenę układu w zakresie jego stabilności (układ jest stabilny, gdy jego bieguny znajdują się w lewej półpłaszczyźnie zespolonej) oraz ocenę, czy układ jest minimalno-fazowy (układ jest minimalno-fazowy, gdy zera znajdują się w lewej pół-płaszczyźnie zespolonej).

$\mathrm{W}$ analizie dynamiki układów liniowych istotną informację uzyskuje się dzięki wykorzystaniu charakterystyk w dziedzinie częstotliwości. Dokonując podstawienia $s=j \cdot \omega$, gdzie $\omega$ jest częstotliwością kołową, do zależności (12) uzyskano macierze transmitancji widmowej w postaci: 


$$
\mathbf{H}(j \cdot \omega)=\left(\mathbf{K}+j \cdot \omega \cdot \mathbf{D}-\omega^{2} \cdot \mathbf{M}\right)^{-1}
$$

Przy założeniu, że zera i bieguny transmitancji są liczbami zespolonymi $\left(z_{j}=\operatorname{Re} z_{j}+j \cdot \operatorname{Im} z_{j} ; p_{i}=\operatorname{Re} p_{i}+j \cdot \operatorname{Im} p_{i}\right)$, biegunom transmitancji przyporządkowuje się $\mathrm{w}$ dziedzinie częstotliwości, częstotliwości rezonansowe $\omega_{i r}$

$$
\omega_{i r}=\sqrt{\left(\operatorname{Re} p_{i}\right)^{2}+\left(\operatorname{Im} p_{i}\right)^{2}}
$$

a zerom transmitancji przyporządkowuje się $\mathrm{w}$ dziedzinie częstotliwości, częstotliwości anty-rezonansowe $\omega_{\text {jar }}$

$$
\omega_{j a r}=\sqrt{\left(\operatorname{Re} z_{j}\right)^{2}+\left(\operatorname{Im} z_{j}\right)^{2}}
$$

Dla oceny zjawisk zachodzących w układzie wykorzystano charakterystykę amplitudowo-częstotliwościową:

$$
\begin{aligned}
& \left|h_{i j}(j \cdot \omega)\right|=A_{i j}(\omega)= \\
& \sqrt{\left(\operatorname{Re} h_{i j}(j \cdot \omega)\right)^{2}+\left(\operatorname{Im} h_{i j}(j \cdot \omega)\right)^{2}}
\end{aligned}
$$

oraz charakterystykę fazowo-częstotliwościową:

$$
\varphi_{i j}(\omega)=\arctan \frac{\operatorname{Im} h_{i j}(j \cdot \omega)}{\operatorname{Re} h_{i j}(j \cdot \omega)}
$$

\section{Przykład obliczeniowy}

Jako układ podstawowy, poddany następnie modyfikacji, przyjęto dyskretny model belki wspornikowej, opisany trójwymiarowym wektorem współrzędnych uogólnionych $\mathbf{q}$

$$
\mathbf{q}(t)=\left[\begin{array}{l}
q_{1}(t) \\
q_{2}(t) \\
q_{3}(t)
\end{array}\right]
$$

co przedstawiono na rys. 1 .

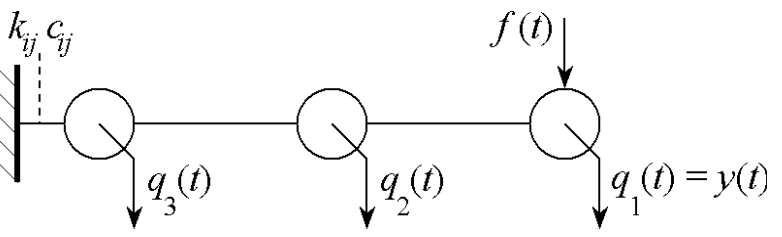

Rys. 1. Dyskretny model układu podstawowego.

Macierz sztywności $\mathbf{K}$ wyznaczono za pomocą metody sił, a macierz mas $\mathbf{M}$ - wykorzystując metodę mas skupionych. Otrzymano wartości:

$$
\begin{gathered}
\mathbf{K}=\left[\begin{array}{ccc}
0,129 & -0,295 & 0,222 \\
-0,295 & 0,813 & -0,850 \\
0,222 & -0,850 & 1,477
\end{array}\right] \cdot 10^{5} \\
\mathbf{M}=\operatorname{diag}\left[\begin{array}{l}
0,2 \\
1,0 \\
1,0
\end{array}\right]
\end{gathered}
$$

Macierz thumienia wewnętrznego D w belce przyjęto w postaci thumienia proporcjonalnego:

$$
\mathbf{D}=\alpha \cdot \mathbf{K}+\beta \cdot \mathbf{M}
$$

gdzie wartości współczynników $\alpha$ i $\beta$ przyjęto według [1]:

$$
\alpha=0,0001, \beta=1
$$

Założono, że konieczna jest modyfikacja charakterystyk sztywnościowych i tłumieniowych układu w celu uzyskania odpowiednich wartości częstotliwości rezonansowych $\omega_{r i}$ i częstotliwości anty-rezonansowych $\omega_{\text {arj }}$.

Modyfikacje struktury układu przeprowadzono poprzez podparcie belki wspornikowej (układ podstawowy) za pomocą:

1॰ liniowej sprężyny:

- na kierunku współrzędnej uogólnionej $q_{1}(t)$ - wariant A,

- na kierunku współrzędnej uogólnionej $q_{2}(t)$ - wariant $\mathrm{B}$,

$2 \circ$ tłumika wiskotycznego:

- na kierunku współrzędnej uogólnionej $q_{1}(t)$ - wariant $\mathrm{C}$,

- na kierunku współrzędnej uogólnionej $q_{2}(t)$ - wariant D.

Przyjęto dwie wartości współczynnika sztywności sprężyny $k_{1}=4000\left[\frac{N}{m}\right] \quad$ i $\quad k_{2}=8000\left[\frac{N}{m}\right] \quad$ oraz dwie wartości współczynnika thumienia thumika $d_{1}=10\left[\frac{\mathrm{N} \cdot \mathrm{s}}{\mathrm{m}}\right] \quad \mathrm{i}$ $d_{2}=15\left[\frac{N \cdot s}{m}\right]$.

Badania przeprowadzono dla przypadków, gdy wejście w postaci siły obciążającej oraz wyjście w postaci przemieszczenia związane były $\mathrm{z}$ kierunkiem tej samej współrzędnej uogólnionej, odpowiednio $q_{1}(t)$ lub $q_{2}(t)$. Macierz wejść ma postać:

$$
\mathbf{B}=\left[\begin{array}{l}
1 \\
0 \\
0
\end{array}\right] \text { lub }\left[\begin{array}{l}
0 \\
1 \\
0
\end{array}\right]
$$

a macierz wyjść:

$$
\mathbf{C}=\left[\begin{array}{lll}
1 & 0 & 0
\end{array}\right] \text { lub }\left[\begin{array}{lll}
0 & 1 & 0
\end{array}\right]
$$

Wielkości otrzymywane podczas analizy zapisywano za pomocą uogólnionego symbolu $X w_{W} Y$ gdzie:

$w$ - badana wielkość (bieguny, zera, częstotliwość ...),

$W$ - przyjęty wariant układu (A, B, C lub D),

$X$ - przypadek współczynnika sztywności (tłumienia),

$Y$ - kierunek współrzędnej uogólnionej związanej $\mathrm{z}$ wejściem i wyjściem układu.

Przykładowo, $1 z_{A} 2$ oznacza zero transmitancji wyznaczonej dla wariantu A układu (belka wspornikowa podparta sprężyną na kierunku współrzędnej $q_{1}$ ) sprężyną o stałej $k_{1}$, a wejście i wyjście związane są z kierunkiem współrzędnej uogólnionej $q_{2}$.

Schematy układu zmodyfikowanego odpowiadające wariantom badawczym przedstawiono na rys. $2 \mathrm{a}$, rys. $2 \mathrm{~b}$, rys. $2 \mathrm{c}$ oraz rys. $2 \mathrm{~d}$. 


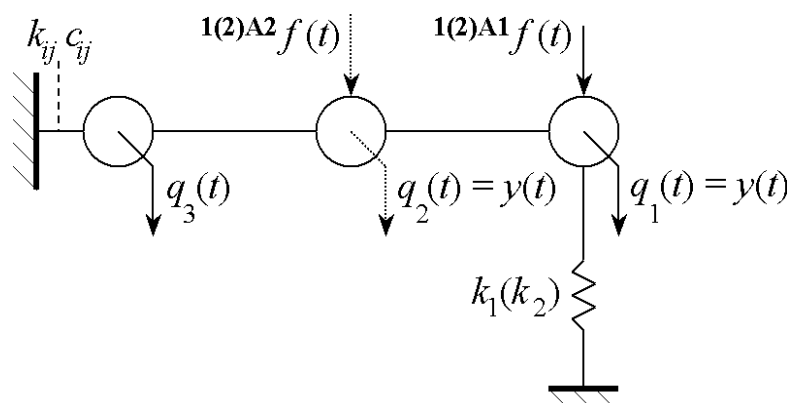

Rys. 2a. Dyskretny model układu zmodyfikowanego według wariantu A

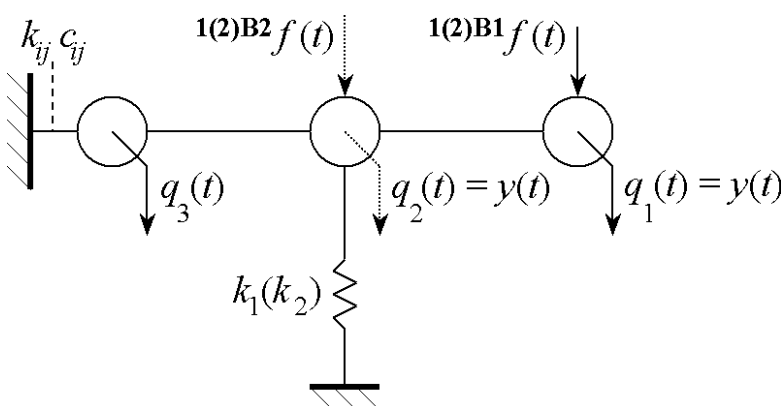

Rys. 2b. Dyskretny model układu zmodyfikowanego według wariantu B

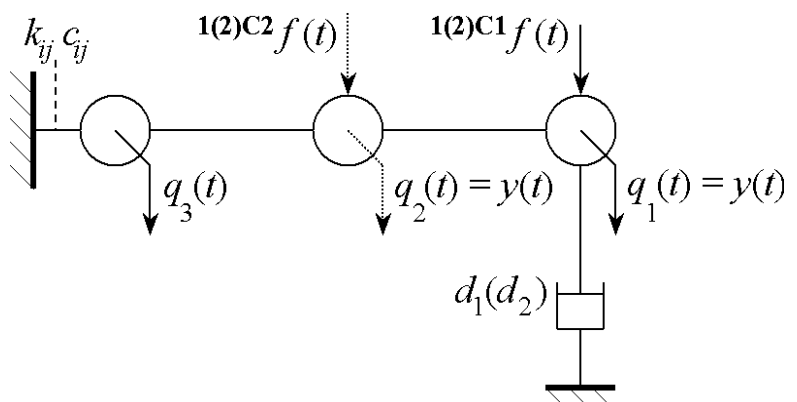

Rys. 2c. Dyskretny model układu zmodyfikowanego według wariantu $\mathrm{C}$

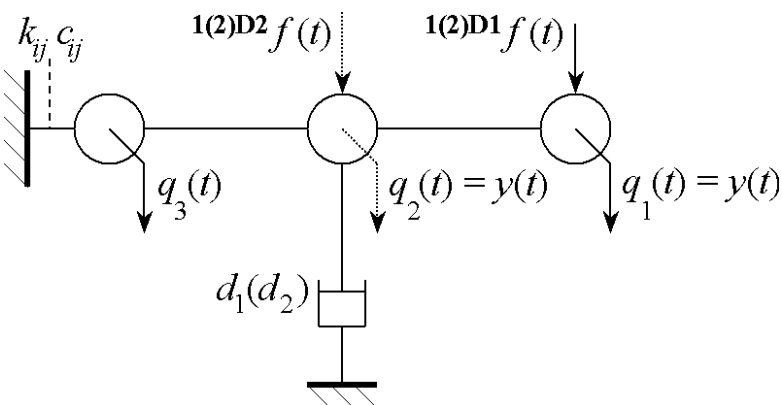

Rys. 2d. Dyskretny model układu zmodyfikowanego według wariantu D

3.1. Bieguny i zera transmitancji dla belki wspornikowej (dla ukladu podstawowego)

Skalarne funkcje reprezentujące przekątną macierzy transmitancji wyznaczono wykorzystując zależność (12):

$$
\mathrm{h} 1(s)=\frac{\sum_{i=0}^{4} a 1_{i} \cdot s^{i}}{\sum_{j=0}^{6} b_{j} \cdot s^{j}}
$$

$$
\begin{array}{r}
\mathrm{h} 2(s)=\frac{\sum_{i=0}^{4} a 2_{i} \cdot s^{i}}{\sum_{j=0}^{6} b_{j} \cdot s^{j}} \\
\mathrm{~h} 3(s)=\frac{\sum_{i=0}^{4} a 3_{i} \cdot s^{i}}{\sum_{j=0}^{6} b_{j} \cdot s^{j}}
\end{array}
$$

gdzie współczynniki przy kolejnych potęgach zmiennej operatorowej s w liczniku i w mianowniku zapisano w postaci wektorów:

$$
\begin{aligned}
\mathrm{a} 1 & =\left[\begin{array}{lllll}
4,8 \mathrm{e} 18 & 1,6 \mathrm{e} 15 & 2,3 \mathrm{e} 14 & 2,1 \mathrm{e} 10 & 1,0 \mathrm{e} 9
\end{array}\right] \\
\mathrm{a} 2 & =\left[\begin{array}{lllll}
1,4 \mathrm{e} 18 & 3,5 \mathrm{e} 14 & 4,2 \mathrm{e} 13 & 4,1 \mathrm{e} 9 & 2,0 \mathrm{e} 8
\end{array}\right] \\
\mathrm{a} 3 & =\left[\begin{array}{lllll}
1,8 \mathrm{e} 18 & 1,6 \mathrm{e} 14 & 2,9 \mathrm{e} 13 & 3,5 \mathrm{e} 9 & 2,0 \mathrm{e} 8
\end{array}\right] \\
\mathrm{b}= & {\left[\begin{array}{lllll}
4,4 \mathrm{e} 21 & 1,3 \mathrm{e} 19 & 2,5 \mathrm{e} 18 & 8,4 \mathrm{e} 14 & \\
& & 5,8 \mathrm{e} 13 & 5,9 \mathrm{e} 9 & 2,0 \mathrm{e} 8
\end{array}\right] }
\end{aligned}
$$

Bieguny transmitancji $p_{i}$ wyznaczono jako pierwiastki wielomianu mianownika transmitancji, a zera transmitancji $z_{j}$ jako pierwiastki wielomianu licznika transmitancji.

Wartości biegunów transmitancji układu podstawowego zebrano $\mathrm{w}$ tabeli 1a, a wartości zer transmitancji układu zebrano w tabeli $1 \mathrm{~b}$.

\section{Wartości biegunów transmitancji układu podstawowego}

Tabela 1a

\begin{tabular}{|c|c|}
\hline \multirow{2}{*}{$i$} & Bieguny \\
\cline { 2 - 3 } & $p_{i}$ \\
\hline 1 & $-8,5 \pm \mathrm{j} \cdot 490,8$ \\
\hline 2 & $-3,7 \pm \mathrm{j} \cdot 225,0$ \\
\hline 3 & $-2,5 \pm \mathrm{j} \cdot 42,5$ \\
\hline
\end{tabular}

Wartości zer transmitancji układu podstawowego

Tabela 1b

\begin{tabular}{|c|c|c|c|}
\hline \multirow{2}{*}{$j$} & $z_{j} 1$ & $z_{j} 2$ & $z_{j} 3$ \\
\cline { 2 - 4 } & $-7,6 \pm \mathrm{j} \cdot 453,5$ & $-6,7 \pm \mathrm{j} \cdot 413,0$ & $-5,9 \pm \mathrm{j} \cdot 373,3$ \\
\hline 1 & $-3,1 \pm \mathrm{j} \cdot 152,4$ & $-3,5 \pm \mathrm{j} \cdot 203,0$ & $-2,6 \pm \mathrm{j} \cdot 79,9$ \\
\hline 2 & \multicolumn{3}{|c|}{} \\
\hline
\end{tabular}

Ze względu na to, że bieguny i zera transmitancji są liczbami zespolonymi, przypisuje się im fizyczną interpretację jako częstotliwości rezonansowe $\omega_{i r}$ dla biegunów transmitancji oraz jako częstotliwości antyrezonansowe $\omega_{j a r}$ dla zer transmitancji.

Wartości częstotliwości rezonansowych układu podstawowego zebrano w tabeli $2 \mathrm{a}$, a częstotliwości antyrezonansowych $\mathrm{w}$ tabeli $2 \mathrm{~b}$. 
Wartości częstotliwości rezonansowych

\begin{tabular}{|c|c|}
\hline \multirow{2}{*}{$i$} & Częstotliwości rezonansowe $[\mathrm{rad} / \mathrm{s}]$ \\
\cline { 2 - 3 } & $\omega_{i r}$ \\
\hline 1 & 490,9 \\
\hline 2 & 225,0 \\
\hline 3 & 42,6 \\
\hline
\end{tabular}

Wartości częstotliwości antyrezonansowych

Tabela 2b

\begin{tabular}{|c|c|c|c|}
\hline \multirow{2}{*}{$j$} & \multicolumn{3}{|c|}{ Częstotliwości anty-rezonansowe $[\mathrm{rad} / \mathrm{s}]$} \\
\cline { 2 - 4 } & $\omega_{j a r} 1$ & $\omega_{j a r} 2$ & $\omega_{j a r} 3$ \\
\hline 1 & 453,6 & 413,3 & 373,3 \\
\hline 2 & 152,5 & 203,3 & 80,0 \\
\hline
\end{tabular}

Poglądową informację o charakterze zjawisk zachodzących w układzie uzyskuje się na podstawie analizy położenia biegunów i zer transmitancji na płaszczyźnie zespolonej. Rozkład zer i biegunów transmitancji układu podstawowego, dla przypadku gdy wyjście i wejście układu związano z kierunkiem współrzędnej uogólnionej $q_{1}(t)$, przedstawiono na rysunku $3 \mathrm{a}$, a gdy związano z kierunkiem współrzędnej uogólnionej $q_{2}(t)$ - na rysunku 3 b.

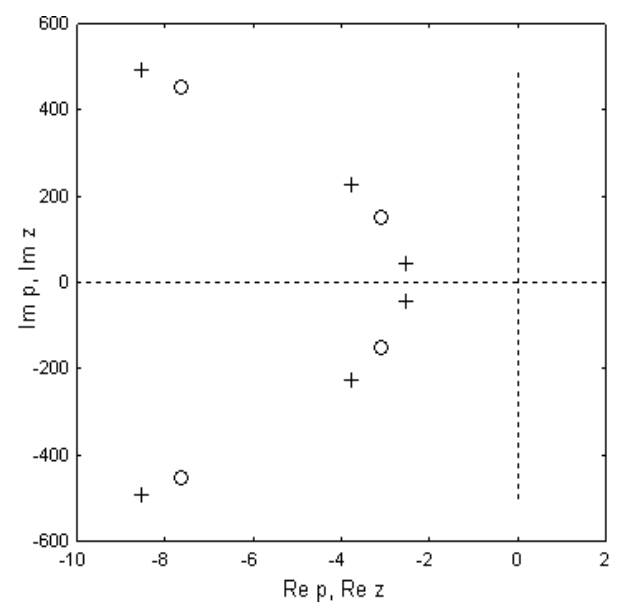

Rys. 3a. Położenie biegunów $p_{i}(+)$ oraz zer $z_{j} 1(\mathrm{O})$ transmitancji układu podstawowego.

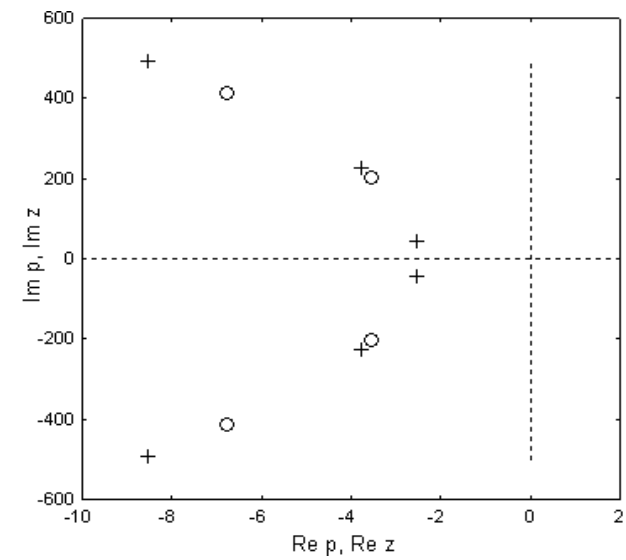

Rys. 3b. Położenie biegunów $p_{i}(+)$ oraz zer $z_{j} 2(\mathrm{O})$ transmitancji układu podstawowego.
Do wyznaczonych wartości zer i biegunów transmitancji oraz wartości częstotliwości rezonansowych i antyrezonansowych układu podstawowego odnoszone będę zmiany tych wielkości wynikające z modyfikacji układu. Rozkłady zer i biegunów transmitancji układu podstawowego na płaszczyźnie zespolonej są typowe dla układów z niewielkim tłumieniem - charakterystyczną cechą jest przemienność położenia zer i biegunów.

\subsection{Bieguny i zera transmitancji układu, w którym belka wspornikowa podparta jest liniową sprężyną}

W wyniku podparcia belki wspornikowej liniową sprężyną o współczynniku sztywności $k_{1}$ (wariantowo $k_{2}$ ) na kierunku współrzędnej uogólnionej $q_{1}(t)$, zmianie uległa, odpowiednio do wariantu, wartość elementu $k_{11}$ macierzy sztywności $\mathbf{K}$ :

$$
k_{11}=16900\left[\frac{N}{m}\right] \quad\left(k_{11}=20900\left[\frac{N}{m}\right]\right)
$$

Skalarne funkcje reprezentujące przekątną macierzy transmitancji wyznaczono wykorzystując zależność (12). Dla badanych wariantów: 1A1, 1A2, 2A1 oraz 2A2, mają one postać:

$$
\begin{aligned}
1 \mathrm{~h}_{A} 1(s) & =\frac{\sum_{i=0}^{4} 1 a_{A} 1_{i} \cdot s^{i}}{\sum_{j=0}^{6} 1 b_{A j} \cdot s^{j}} \\
1 \mathrm{~h}_{A} 2(s) & =\frac{\sum_{i=0}^{4} 1 a_{A} 2_{i} \cdot s^{i}}{\sum_{j=0}^{6} 1 b_{A j} \cdot s^{j}} \\
2 \mathrm{~h}_{A} 1(s)= & \frac{\sum_{i=0}^{4} 2 a_{A} 1_{i} \cdot s^{i}}{\sum_{j=0}^{6} 2 b_{A j} \cdot s^{j}} \\
2 \mathrm{~h}_{A} 2(s)= & \frac{\sum_{i=0}^{4} 2 a_{A} 2_{i} \cdot s^{i}}{\sum_{j=0}^{6} 2 b_{A j} \cdot s^{j}}
\end{aligned}
$$

gdzie współczynniki przy kolejnych potęgach zmiennej operatorowej s w liczniku i w mianowniku zapisano $\mathrm{w}$ postaci wektorów:

$$
\begin{aligned}
\mathbf{1 a}_{\mathbf{A}} \mathbf{1} & =\left[\begin{array}{lllll}
4,8 e 18 & 1,6 e 15 & 2,3 e 14 & 2,1 e 10 & 1,0 e 9
\end{array}\right] \\
\mathbf{1 a}_{\mathbf{A}} \mathbf{2} & =\left[\begin{array}{lllll}
2,0 e 18 & 4,0 e 14 & 4,6 e 13 & 4,1 e 9 & 2,0 e 8
\end{array}\right] \\
\mathbf{1} \mathbf{b}_{\mathbf{A}} & =\left[\begin{array}{llll}
2,3 e 22 & 1,9 e 19 & 3,4 e 18 & 9,3 e 14 \\
6,3 e 13 & 5,9 e 9 & 2,0 e 8
\end{array}\right] \\
\mathbf{2 a}_{\mathbf{A}} \mathbf{1} & =\left[\begin{array}{lllll}
4,8 e 18 & 1,6 e 15 & 2,3 e 14 & 2,1 e 10 & 1,0 e 9
\end{array}\right] \\
\mathbf{2 a}_{\mathbf{A}} \mathbf{2} & =\left[\begin{array}{lllll}
2,6 e 18 & 4,5 e 14 & 5,0 e 13 & 4,1 e 9 & 2,0 e 8
\end{array}\right] \\
\mathbf{2 b}_{\mathbf{A}} & =\left[\begin{array}{llll}
4,3 e 22 & 2,6 e 19 & 4,4 e 18 & 1,0 e 15
\end{array}\right.
\end{aligned}
$$

Bieguny $1 p_{A i}, 2 p_{A i}$ transmitancji wyznaczono jako pierwiastki wielomianu mianownika transmitancji, a zera $1 z_{A} 1_{j}, 1 z_{A} 2_{j}, 2 z_{A} 1_{j}, 2 z_{A} 2_{j}$ transmitancji jako 
pierwiastki wielomianu licznika transmitancji.

Wartości biegunów transmitancji układu zebrano w tabeli 3a, a wartości zer transmitancji zebrano w tabeli $3 \mathrm{~b}$.

Wartości biegunów transmitancji układu

Tabela 3a

\begin{tabular}{|c|c|c|}
\hline \multirow{2}{*}{$i$} & $1 p_{A i}$ Bieguny \\
\cline { 2 - 3 } & $-8,5 \pm \mathrm{j} \cdot 494,6$ & $2 p_{A i}$ \\
\hline 1 & $-3,7 \pm \mathrm{j} \cdot 246,7$ & $-8,5 \pm \mathrm{j} \cdot 498,9$ \\
\hline 2 & $-2,6 \pm \mathrm{j} \cdot 88,9$ & $-3,7 \pm \mathrm{j} \cdot 269,6$ \\
\hline 3 & & $-2,6 \pm \mathrm{j} \cdot 108,5$ \\
\hline
\end{tabular}

Wartości zer transmitancji układu

Tabela 3b

\begin{tabular}{|c|c|c|c|c|}
\hline \multirow{2}{*}{$j$} & \multicolumn{4}{|c|}{ Zera } \\
\cline { 2 - 5 } & $1 z_{A} 1_{j}$ & $1 z_{A} 2_{j}$ & $2 z_{A} 1_{j}$ & $2 z_{A} 2_{j}$ \\
\hline 1 & $-7,6$ & $-6,7$ & $-7,6$ & $-6,7$ \\
& $\pm \mathrm{j} \cdot 453,5$ & $\pm \mathrm{j} \cdot 418,2$ & $\pm \mathrm{j} \cdot 453,5$ & $\pm \mathrm{j} \cdot 424,5$ \\
\hline 2 & $-3,1$ & $-3,5$ & $-3,1$ & $-3,6$ \\
& $\pm \mathrm{j} \cdot 152,4$ & $\pm \mathrm{j} \cdot 239,2$ & $\pm \mathrm{j} \cdot 152,4$ & $\pm \mathrm{j} \cdot 268,2$ \\
\hline
\end{tabular}

Ze względu na to, że bieguny i zera transmitancji są liczbami zespolonymi, przypisuje się im fizyczną interpretację jako częstotliwości rezonansowe $1 \omega_{\text {Air }}, 2 \omega_{\text {Air }}$ dla biegunów transmitancji oraz jako częstotliwości antyrezonansowe $1 \omega_{A j a r} 1,1 \omega_{A j a r} 2,2 \omega_{A j a r} 1$ i $2 \omega_{A j a r} 2$ dla zer transmitancji.

Wartości częstotliwości rezonansowych układu zebrano w tabeli 4a, a częstotliwości anty-rezonansowych w tabeli 4b.

Wartości częstotliwości rezonansowych

Tabela 4a

\begin{tabular}{|c|c|c|}
\hline \multirow{2}{*}{$i$} & \multicolumn{2}{|c|}{ Częstotliwości rezonansowe [rad/s] } \\
\cline { 2 - 3 } & $1 \omega_{\text {Air }}$ & $2 \omega_{\text {Air }}$ \\
\hline 1 & 494,6 & 498,9 \\
\hline 2 & 246,8 & 269,6 \\
\hline 3 & 88,9 & 108,6 \\
\hline
\end{tabular}

Wartości częstotliwości anty-

Tabela 4b rezonansowych

\begin{tabular}{|c|c|c|c|c|}
\hline \multirow{2}{*}{$j$} & \multicolumn{5}{|c|}{ Częstotliwości anty-rezonansowe [rad/s] } \\
\cline { 2 - 5 } & $1 \omega_{\text {Ajar }} 1$ & $1 \omega_{\text {Ajar }} 2$ & $2 \omega_{\text {Ajar }} 1$ & $2 \omega_{\text {Ajar }} 2$ \\
\hline 1 & 453,6 & 418,2 & 453,6 & 424,5 \\
\hline 2 & 152,5 & 239,3 & 152,5 & 268,3 \\
\hline
\end{tabular}

Poglądową informację o charakterze zjawisk zachodzących w układzie uzyskuje się na podstawie analizy położenia biegunów i zer transmitancji na płaszczyźnie zespolonej. Rozkład zer i biegunów transmitancji badanego układu (sztywność sprężyny $k_{2}=8000\left[\frac{N}{m}\right]$ ), dla przypadku, gdy wyjście i wejście układu związano $\mathrm{z}$ kierunkiem współrzędnej uogólnionej $q_{1}(t)$, przedstawiono na rysunku 4a, a gdy związano z kierunkiem współrzędnej uogólnionej $q_{2}(t)$ - na rysunku $4 \mathrm{~b}$.

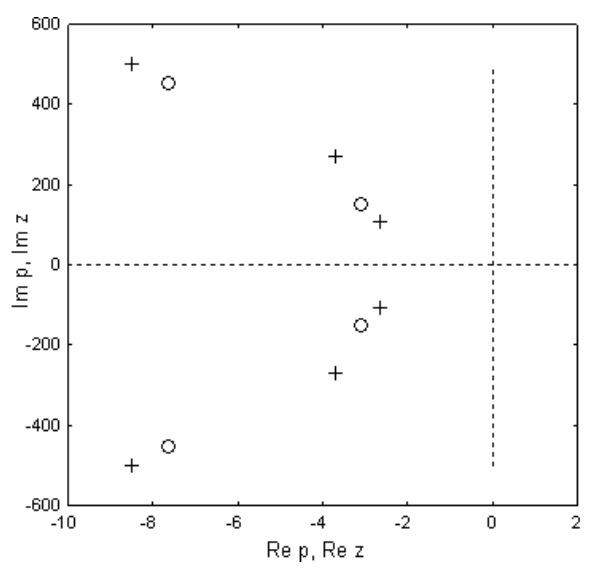

Rys. 4a. Położenie biegunów $2 p_{A i}(+)$ oraz zer $2 z_{A j} 1$ (O) transmitancji układu

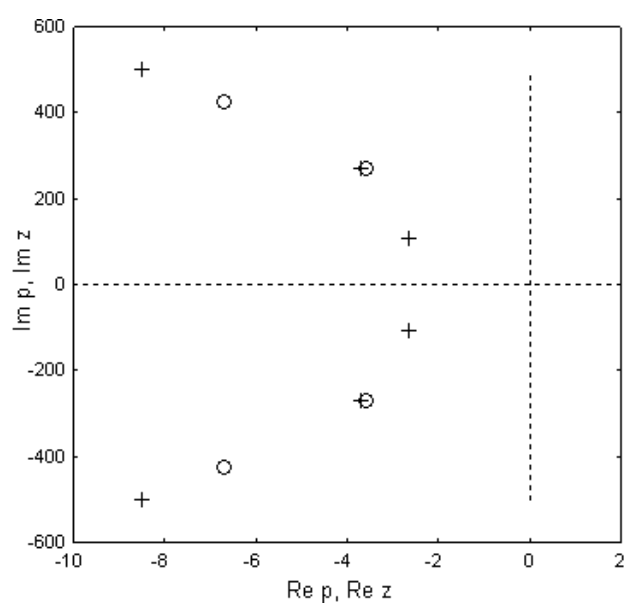

Rys. 4b. Położenie biegunów $2 p_{A i}(+)$ oraz zer $2 z_{A j} 2$ (O) transmitancji układu

W wyniku podparcia belki wspornikowej liniową sprężyną o współczynniku sztywności $k_{1}$ (wariantowo $k_{2}$ ) na kierunku współrzędnej uogólnionej $q_{2}(t)$, zmianie uległa, odpowiednio do wariantu, wartość elementu $k_{22}$ macierzy sztywności $\mathbf{K}$ :

$$
k_{22}=85300\left[\frac{N}{m}\right] \quad\left(k_{22}=89300\left[\frac{N}{m}\right]\right)
$$

Skalarne funkcje reprezentujące przekątną macierzy transmitancji wyznaczono wykorzystując zależność (12). Dla badanych wariantów: $1 \mathrm{~B} 1,1 \mathrm{~B} 2,2 \mathrm{~B} 1$ oraz $2 \mathrm{~B} 2$, mają one postać:

$$
\begin{gathered}
1 \mathrm{~h}_{B} 1(s)=\frac{\sum_{i=0}^{4} 1 a_{B} 1_{i} \cdot s^{i}}{\sum_{j=0}^{6} 1 b_{B j} \cdot s^{j}} \\
1 \mathrm{~h}_{B} 2(s)=\frac{\sum_{i=0}^{4} 1 a_{B} 2_{i} \cdot s^{i}}{\sum_{j=0}^{6} 1 b_{B j} \cdot s^{j}}
\end{gathered}
$$




$$
\begin{array}{r}
2 \mathrm{~h}_{B} 1(s)=\frac{\sum_{i=0}^{4} 2 a_{B} 1_{i} \cdot s^{i}}{\sum_{j=0}^{6} 2 b_{B j} \cdot s^{j}} \\
2 \mathrm{~h}_{B} 2(s)=\frac{\sum_{i=0}^{4} 2 a_{B} 2_{i} \cdot s^{i}}{\sum_{j=0}^{6} 2 b_{B j} \cdot s^{j}}
\end{array}
$$

gdzie współczynniki przy kolejnych potęgach zmiennej operatorowej $\mathrm{s}$ w liczniku $\mathrm{i}$ w mianowniku zapisano $\mathrm{w}$ postaci wektorów:

$$
\begin{aligned}
\mathbf{1} \mathbf{a}_{\mathbf{B}} \mathbf{1} & =\left[\begin{array}{lllll}
5,4 e 18 & 1,7 e 15 & 2,3 e 14 & 2,1 e 10 & 1,0 e 9
\end{array}\right] \\
\mathbf{1 a}_{\mathbf{B}} \mathbf{2} & =\left[\begin{array}{lllll}
1,4 e 18 & 3,5 e 14 & 4,2 e 13 & 4,1 e 9 & 2,0 e 8
\end{array}\right] \\
\mathbf{1} \mathbf{b}_{\mathbf{B}} & =\left[\begin{array}{lllll}
1,0 e 22 & 1,5 e 19 & 2,7 e 18 & 8,6 e 14 \\
5,9 e 13 & 5,9 e 9 & 2,0 e 8
\end{array}\right] \\
\mathbf{2} \mathbf{a}_{\mathbf{B}} \mathbf{1} & =\left[\begin{array}{lllll}
5,9 e 18 & 1,7 e 15 & 2,4 e 14 & 2,1 e 10 & 1,0 e 9
\end{array}\right] \\
\mathbf{2 a}_{\mathbf{B}} \mathbf{2} & =\left[\begin{array}{lllll}
1,4 e 18 & 3,5 e 14 & 4,2 e 13 & 4,1 e 9 & 2,0 e 8
\end{array}\right] \\
\mathbf{2 b}_{\mathbf{B}} & =\left[\begin{array}{llll}
1,6 e 22 & 1,6 e 19 & 2,9 e 18 & 8,7 e 14
\end{array}\right.
\end{aligned}
$$

Bieguny transmitancji $1 p_{B i}, 2 p_{B i}$ wyznaczono jako pierwiastki wielomianu mianownika transmitancji, a zera transmitancji $1 z_{B} 1_{j}, 1 z_{B} 2_{j}, 2 z_{B} 1_{j}$ oraz $2 z_{B} 2_{j}$ jako pierwiastki wielomianu licznika transmitancji.

Wartości biegunów transmitancji układu zebrano w tabeli $5 \mathrm{a}$, a wartości zer transmitancji zebrano $\mathrm{w}$ tabeli $5 \mathrm{~b}$.

\section{Wartości biegunów transmitancji układu Tabela 5a}

\begin{tabular}{|c|c|c|}
\hline \multirow{2}{*}{$i$} & \multicolumn{2}{|c|}{ Bieguny } \\
\cline { 2 - 3 } & $1 p_{B i}$ & $2 p_{B i}$ \\
\hline 1 & $-8,5 \pm \mathrm{j} \cdot 492,1$ & $-8,5 \pm \mathrm{j} \cdot 493,4$ \\
\hline 2 & $-3,8 \pm \mathrm{j} \cdot 226,1$ & $-3,8 \pm \mathrm{j} \cdot 227,3$ \\
\hline 3 & $-2,2 \pm \mathrm{j} \cdot 83,7$ & $-2,5 \pm \mathrm{j} \cdot 78,9$ \\
\hline
\end{tabular}

Wartości zer transmitancji układu

Tabela $5 b$

\begin{tabular}{|c|c|c|c|c|}
\hline \multirow{2}{*}{$j$} & \multicolumn{4}{|c|}{ Zera } \\
\cline { 2 - 5 } & $1 z_{B} 1_{j}$ & $1 z_{B} 2_{j}$ & $2 z_{B} 1_{j}$ & $2 z_{B} 2_{j}$ \\
\hline 1 & $\begin{array}{c}-7,6 \\
\pm \mathrm{j} \cdot 454,9\end{array}$ & $-6,7$ & $-7,6$ & $-6,7$ \\
& $\pm \mathrm{j} \cdot 413,3$ & $\pm \mathrm{j} \cdot 456,4$ & $\pm \mathrm{j} \cdot 413,3$ \\
\hline 2 & $-3,1$ & $-3,5$ & $-3,1$ & $-3,5$ \\
& $\pm \mathrm{j} \cdot 161,1$ & $\pm \mathrm{j} \cdot 203,3$ & $\pm \mathrm{j} \cdot 169,1$ & $\pm \mathrm{j} \cdot 203,3$ \\
\hline
\end{tabular}

Ze względu na to, że bieguny i zera transmitancji sa liczbami zespolonymi, przypisuje się im fizyczną interpretację jako częstotliwości rezonansowe $1 \omega_{\text {Bir }}$, $2 \omega_{\text {Bir }}$ dla biegunów transmitancji oraz jako częstotliwości anty-rezonansowe $1 \omega_{\text {Bjar }} 1, \quad 1 \omega_{\text {Bjar }} 2,2 \omega_{\text {Bjar }} 1$ oraz $2 \omega_{\text {Bjar }} 2$ dla zer transmitancji.

Wartości częstotliwości rezonansowych układu zebrano $\mathrm{w}$ tabeli $6 \mathrm{a}$, a częstotliwości anty-rezonansowych w tabeli $6 \mathrm{~b}$.
Wartości częstotliwości rezonansowych

Tabela 6a

\begin{tabular}{|c|c|c|}
\hline \multirow{2}{*}{$i$} & \multicolumn{2}{|c|}{ Czesstotliwości rezonansowe $\lceil\mathrm{rad} / \mathrm{s}\rceil$} \\
\cline { 2 - 3 } & $1 \omega_{\text {Bir }}$ & $2 \omega_{\text {Bir }}$ \\
\hline 1 & 492,2 & 493,5 \\
\hline 2 & 226,2 & 227,4 \\
\hline 3 & 63,8 & 79,0 \\
\hline
\end{tabular}

Wartości częstotliwości antyrezonansowych

Tabela 6 b

\begin{tabular}{|c|c|c|c|c|}
\hline \multirow{2}{*}{$j$} & \multicolumn{5}{|c|}{ Czestotliwości anty-rezonansowe $[\mathrm{rad} / \mathrm{s}]$} \\
\cline { 2 - 5 } & $1 \omega_{\text {Bjar }} 1$ & $1 \omega_{\text {Bjar }} 2$ & $2 \omega_{\text {Bjar }} 1$ & $2 \omega_{\text {Bjar }} 2$ \\
\hline 1 & 455,0 & 413,4 & 456,5 & 413,4 \\
\hline 2 & 161,1 & 203,3 & 169,2 & 203,3 \\
\hline
\end{tabular}

Poglądową informację o charakterze zjawisk zachodzących w układzie uzyskuje się na podstawie analizy położenia biegunów i zer transmitancji na płaszczyźnie zespolonej. Rozkład zer i biegunów transmitancji badanego układu (sztywność sprężyny $k_{2}=8000\left[\frac{N}{m}\right]$ ), dla przypadku gdy wyjście i wejście układu związano $z$ kierunkiem współrzędnej uogólnionej $q_{1}(t)$, przedstawiono na rysunku 5a, a gdy związano z kierunkiem współrzędnej uogólnionej $q_{2}(t)$ - na rysunku 5 b.

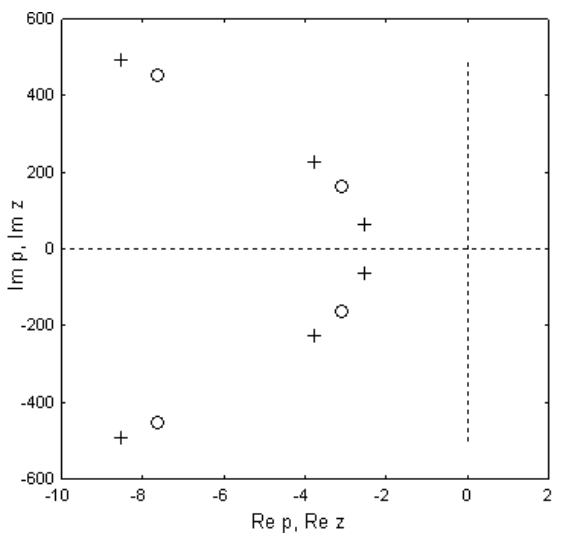

Rys. 5a. Położenie biegunów $2 p_{B i}(+)$ oraz zer $2 z_{B j} 1$ (O) transmitancji układu

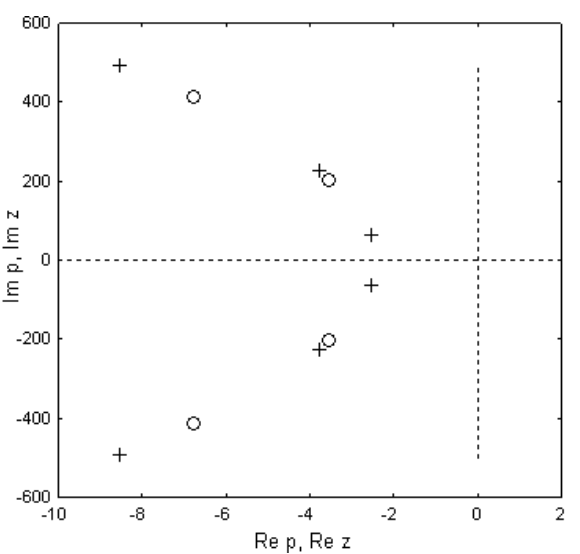

Rys. 5b. Położenie biegunów $2 p_{B i}(+)$ oraz zer $2 z_{B j} 2(\mathrm{O})$ transmitancji układu 
W celu przedstawienia wpływu modyfikacji układu za pomocą elementu sztywnościowego na wartości częstotliwości rezonansowych i anty-rezonansowych przeprowadzono analizę częstotliwościową z wykorzystaniem systemu komputerowego [6]. Charakterystyki amplitudowoczęstotliwościowe (w skali decybelowej) wyznaczone dla badanych wariantów przedstawiono na: rys. $6 a$, rys. $6 \mathrm{~b}$, rys. $6 \mathrm{c}$ oraz rys. $6 \mathrm{~d}$.

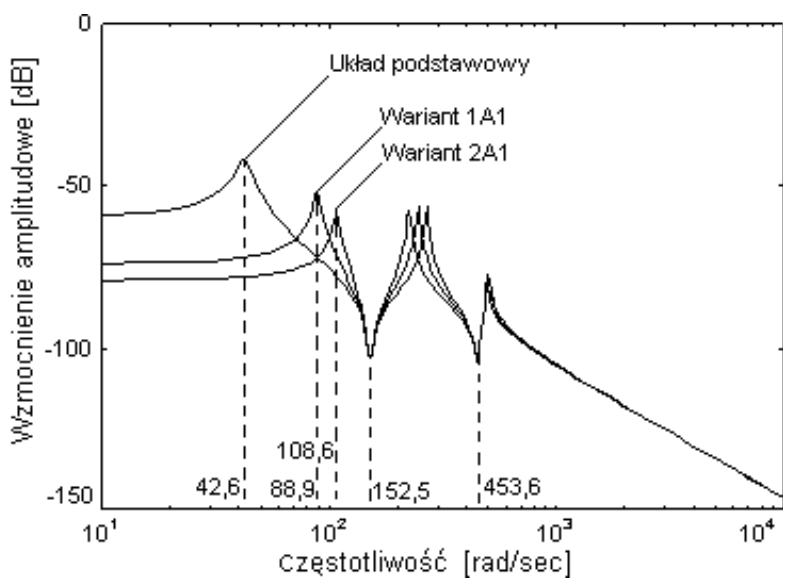

Rys. 6a. Decybelowe charakterystyki wzmocnienia dla układu podstawowego i wariantów $1 \mathrm{~A} 1$ oraz $2 \mathrm{~A} 1$ układu zmodyfikowanego

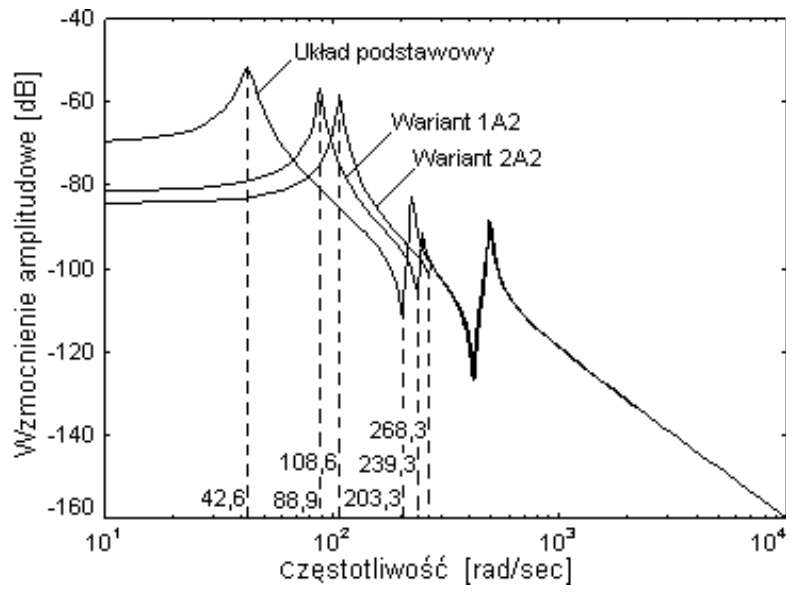

Rys. 6b. Decybelowe charakterystyki wzmocnienia dla układu podstawowego i wariantów $1 \mathrm{~A} 2$ oraz $2 \mathrm{~A} 2 \mathrm{układu}$ zmodyfikowanego

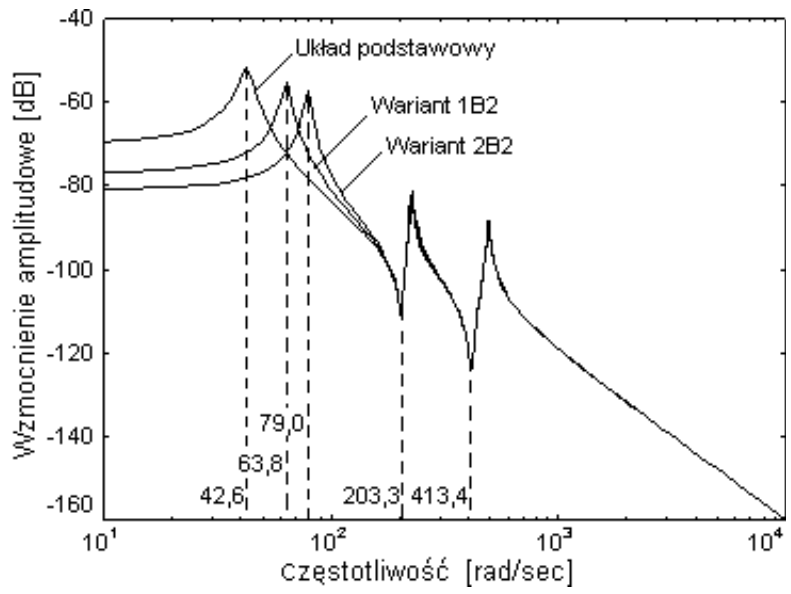

Rys. 6c. Decybelowe charakterystyki wzmocnienia dla układu podstawowego i wariantów 1B2 oraz 2B2 układu zmodyfikowanego

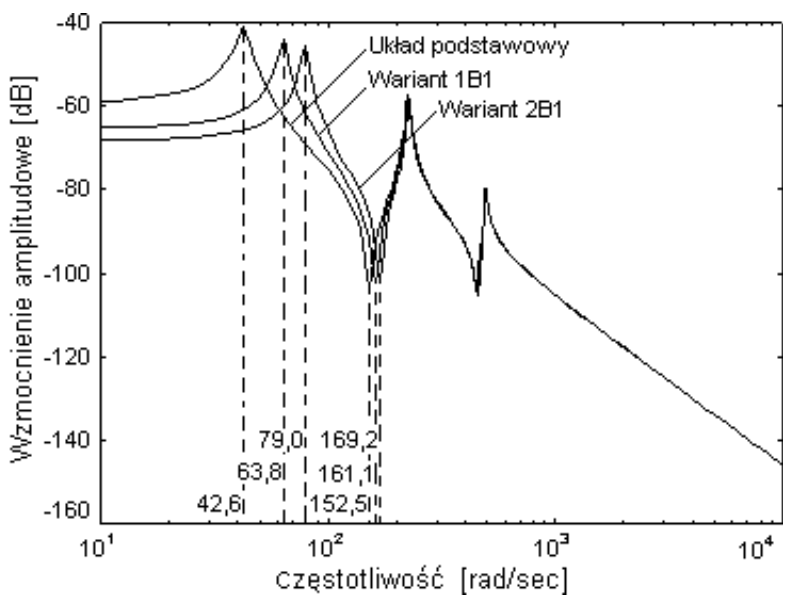

Rys. 6d. Decybelowe charakterystyki wzmocnienia dla układu podstawowego i wariantów $1 \mathrm{~B} 1$ oraz 2B1 układu zmodyfikowanego

Modyfikacja układu za pomocą elementu sztywnościowego (sprężyna śrubowa) powoduje zmiany położenia biegunów (wartości częstotliwości rezonansowych) oraz zmiany położenia zer (wartości częstotliwości antyrezonansowych). Na wartości zer i wartości częstotliwości anty-rezonansowych istotny wpływ ma postać wektora wejść i wektora wyjść.

Modyfikacja układu za pomocą elementu sztywnościowego nie zmienia formy rozkładu zer i biegunów typowego dla układu $\mathrm{z}$ niewielkim tłumieniem - zachowana jest przemienność położenia biegunów i zer.

$\mathrm{Na}$ podstawie analizy wyników stwierdzono, że wartości zer (wartości częstotliwości anty-rezonansowych) nie ulegają zmianie, jeśli modyfikacji podlega charakterystyka sztywnościowa układu na kierunku współrzędnej uogólnionej, na której działa wymuszenie oraz dokonywany jest pomiar. Wpływ lokalizacji elementu podpierającego belkę wspornikową na wartości częstotliwości rezonansowych i anty-rezonansowych jest najlepiej widoczny na wykresach charakterystyk częstotliwościowych.

\subsection{Bieguny i zera transmitancji układu, w którym belka wspornikowa podparta jest tlumikiem wisko- tycznym}

W wyniku podparcia belki wspornikowej tłumikiem wiskotycznym o współczynniku thumienia $d_{1}$ (wariantowo $d_{2}$ ) na kierunku współrzędnej uogólnionej $q_{1}(t)$, zmianie uległa, odpowiednio do wariantu wartość elementu $d_{11}$ macierzy thumienia $\mathbf{D}$ :

$$
d_{11}=11,646\left[\frac{N \cdot s}{m}\right] \quad\left(d_{11}=16,646\left[\frac{N \cdot s}{m}\right]\right)
$$

Skalarne funkcje reprezentujące przekątną macierzy transmitancji wyznaczono wykorzystując zależność (12). Dla badanych wariantów: $1 \mathrm{C} 1,1 \mathrm{C} 2,2 \mathrm{C} 1$ oraz $2 \mathrm{C} 2$, mają one postać:

$$
\begin{aligned}
& 1 \mathrm{~h}_{C} 1(s)=\frac{\sum_{i=0}^{4} 1 a_{C} 1_{i} \cdot s^{i}}{\sum_{j=0}^{6} 1 b_{C j} \cdot s^{j}} \\
& 1 \mathrm{~h}_{C} 2(s)=\frac{\sum_{i=0}^{4} 1 a_{C} 2_{i} \cdot s^{i}}{\sum_{j=0}^{6} 1 b_{C j} \cdot s^{j}}
\end{aligned}
$$




$$
\begin{array}{r}
2 \mathrm{~h}_{C} 1(s)=\frac{\sum_{i=0}^{4} 2 a_{C} 1_{i} \cdot s^{i}}{\sum_{j=0}^{6} 2 b_{C j} \cdot s^{j}} \\
2 \mathrm{~h}_{C} 2(s)=\frac{\sum_{i=0}^{4} 2 a_{C} 2_{i} \cdot s^{i}}{\sum_{j=0}^{6} 2 b_{C j} \cdot s^{j}}
\end{array}
$$

gdzie współczynniki przy kolejnych potęgach zmiennej operatorowej s w liczniku i w mianowniku zapisano w postaci wektorów:

$$
\begin{aligned}
\mathbf{1} \mathbf{a}_{\mathbf{C}} \mathbf{1} & =\left[\begin{array}{lllll}
4,8 e 18 & 1,6 e 15 & 2,3 e 14 & 2,1 e 10 & 1,0 e 9
\end{array}\right] \\
\mathbf{1 a}_{\mathbf{C}} \mathbf{2} & =\left[\begin{array}{lllll}
1,4 e 18 & 1,8 e 15 & 4,3 e 13 & 1,4 e 10 & 2,0 e 8
\end{array}\right] \\
\mathbf{1 b}_{\mathbf{C}} & =\left[\begin{array}{llll}
4,4 e 21 & 6,1 e 19 & 2,6 e 18 & 3,1 e 15 \\
5,9 e 13 & 1,6 e 10 & 2,0 e 8
\end{array}\right] \\
\mathbf{2 a}_{\mathbf{C}} \mathbf{1} & =\left[\begin{array}{lllll}
4,8 e 18 & 1,6 e 15 & 2,3 e 14 & 2,1 e 10 & 1,0 e 9
\end{array}\right] \\
\mathbf{2 a}_{\mathbf{C}} \mathbf{2} & =\left[\begin{array}{lllll}
1,4 e 18 & 2,6 e 15 & 4,3 e 13 & 1,9 e 10 & 2,0 e 8
\end{array}\right] \\
\mathbf{2 b}_{\mathbf{C}} & =\left[\begin{array}{llll}
4,4 e 21 & 8,5 e 19 & 2,6 e 18 & 4,3 e 15 \\
6,9 e 13 & 2,1 e 10 & 2,0 e 8
\end{array}\right]
\end{aligned}
$$

\begin{tabular}{|c|c|c|c|c|}
\hline \multicolumn{4}{|c|}{ Wartości zer transmitancji układu } & abela $7 b$ \\
\hline \multirow[b]{2}{*}{$j$} & \multicolumn{4}{|c|}{ Zera } \\
\hline & $1 z_{C} 1_{j}$ & $1 z_{C} 2_{j}$ & $2 z_{C} 1_{j}$ & $2 z_{C}{ }^{2}$ \\
\hline \multirow[t]{2}{*}{1} & $-7,6$ & $-11,2$ & $-7,6$ & $-13,2$ \\
\hline & $\pm \mathrm{j} .453,5$ & $\pm \mathrm{j} .412,6$ & $\pm \mathrm{j} .453,5$ & $\pm \mathrm{j} .411,9$ \\
\hline \multirow[t]{2}{*}{2} & $-3,1$ & $-24,1$ & $-3,1$ & $-34,6$ \\
\hline & $\pm \mathrm{j} \cdot 152,4$ & $\pm \mathrm{j} \cdot 202,1$ & $\pm \mathrm{j} \cdot 152,4$ & $\pm \mathrm{j} \cdot 201,0$ \\
\hline
\end{tabular}

Bieguny transmitancji $1 p_{C i}, \quad 2 p_{C i}$ wyznaczono jako pierwiastki wielomianu mianownika transmitancji, a zera transmitancji $1 z_{C} 1_{j}, \quad 1 z_{C} 2_{j}, \quad 2 z_{C} 1_{j}$ oraz $2 z_{C} 2_{j}$ jako pierwiastki wielomianu licznika transmitancji.

Wartości biegunów transmitancji układu zebrano w tabeli $7 \mathrm{a}, \mathrm{a}$ wartości zer transmitancji zebrano w tabeli $7 \mathrm{~b}$.

Wartości biegunów transmitancji układu
\begin{tabular}{|c|c|c|}
\hline \multirow{2}{*}{$i$} & \multicolumn{2}{|c|}{ Bieguny } \\
\cline { 2 - 3 } & $1 p_{C i}$ & $2 p_{C i}$ \\
\hline 1 & $-12,7 \pm \mathrm{j} \cdot 494,0$ & $-14,7 \pm \mathrm{j} \cdot 489,8$ \\
\hline 2 & $-15,1 \pm \mathrm{j} \cdot 223,7$ & $-20,7 \pm \mathrm{j} \cdot 222,1$ \\
\hline 3 & $-12,0 \pm \mathrm{j} \cdot 41,1$ & $-16,9 \pm \mathrm{j} \cdot 39,6$ \\
\hline
\end{tabular}

Ze względu na to, że bieguny i zera transmitancji są liczbami zespolonymi, przypisuje się im fizyczną interpretację jako częstotliwości rezonansowe $1 \omega_{\text {Cir }}, 2 \omega_{\text {Cir }}$ dla biegunów transmitancji oraz jako częstotliwości antyrezonansowe $1 \omega_{C j a r} 1,1 \omega_{C j a r} 2,2 \omega_{C j a r} 1$ i $2 \omega_{C j a r} 2$ dla zer transmitancji.

Wartości częstotliwości rezonansowych układu zebrano w tabeli 8a, a częstotliwości anty-rezonansowych w tabeli 8b.

\begin{tabular}{|c|c|c|}
\hline \multirow{2}{*}{$i$} & \multicolumn{2}{|c|}{ Częstotliwości rezonansowe $[\mathrm{rad} / \mathrm{s}]$} \\
\cline { 2 - 3 } & $1 \omega_{\text {Cir }}$ & $2 \omega_{\text {Cir }}$ \\
\hline 1 & 495,0 & 490,0 \\
\hline 2 & 224,2 & 223,0 \\
\hline 3 & 42,8 & 43,0 \\
\hline
\end{tabular}

Wartości częstotliwości anty-

Tabela $8 b$ rezonansowych

\begin{tabular}{|c|c|c|c|c|}
\hline \multirow{2}{*}{$j$} & \multicolumn{4}{|c|}{ Częstotliwości anty-rezonansowe $[\mathrm{rad} / \mathrm{s}]$} \\
\cline { 2 - 5 } & $1 \omega_{\text {Cjar }} 1$ & $1 \omega_{\text {Cjar }} 2$ & $2 \omega_{\text {Cjar }} 1$ & $2 \omega_{\text {Cjar }} 2$ \\
\hline 1 & 453,6 & 412,8 & 453,6 & 412,1 \\
\hline 2 & 152,5 & 203,6 & 152,5 & 203,9 \\
\hline
\end{tabular}

Poglądową informację o charakterze zjawisk zachodzących w układzie uzyskuje się na podstawie analizy położenia biegunów i zer transmitancji na płaszczyźnie zespolonej. Rozkład zer i biegunów transmitancji badanego układu (współczynnik tłumienia $d_{1}=10\left[\frac{N \cdot s}{m}\right]$ ), dla przypadku gdy wyjście i wejście układu związano z kierunkiem współrzędnej uogólnionej $q_{1}(t)$, przedstawiono na rysunku 7a, a gdy związano z kierunkiem współrzędnej uogólnionej $q_{2}(t)$ - na rysunku $7 \mathrm{~b}$.

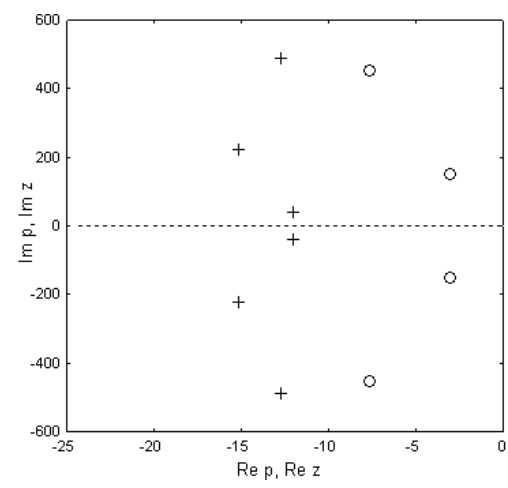

Rys. 7a. Położenie biegunów $2 p_{C i}(+)$ oraz zer $2 z_{C j} 1$ (O) transmitancji układu

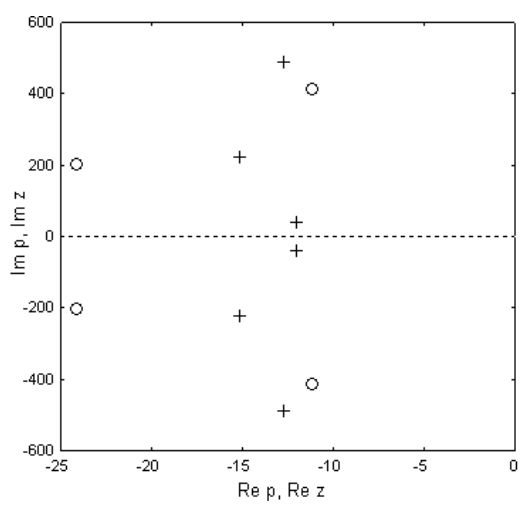

Rys. 7b. Położenie biegunów $2 p_{C i}(+)$ oraz zer $2 z_{C j} 2$ (O) transmitancji układu 
W wyniku podparcia belki wspornikowej tłumikiem wiskotycz-nym o współczynniku tłumienia $d_{1}$ (wariantowo $d_{2}$ ) na kierunku współrzędnej uogólnionej $q_{2}(t)$, zmianie uległa, odpowiednio do wariantu, wartość elementu $d_{22}$ macierzy tłumienia $\mathbf{D}$ :

$$
d_{22}=19,067\left[\frac{N \cdot s}{m}\right] \quad\left(d_{22}=24,067\left[\frac{N \cdot s}{m}\right]\right)
$$

Skalarne funkcje reprezentujące przekątną macierzy transmitancji wyznaczono wykorzystując zależność (12). Dla badanych wariantów: 1D1, 1D2, 2D1 oraz 2D2, mają one postać:

$$
\begin{aligned}
1 \mathrm{~h}_{D} 1(s)= & \frac{\sum_{i=0}^{4} 1 a_{D} 1_{i} \cdot s^{i}}{\sum_{j=0}^{6} 1 b_{D j} \cdot s^{j}} \\
1 \mathrm{~h}_{D} 2(s)= & \frac{\sum_{i=0}^{4} 1 a_{D} 2_{i} \cdot s^{i}}{\sum_{j=0}^{6} 1 b_{D j} \cdot s^{j}} \\
2 \mathrm{~h}_{D} 1(s)= & \frac{\sum_{i=0}^{4} 2 a_{D} 1_{i} \cdot s^{i}}{\sum_{j=0}^{6} 2 b_{D j} \cdot s^{j}} \\
2 \mathrm{~h}_{D} 2(s)= & \frac{\sum_{i=0}^{4} 2 a_{D} 2_{i} \cdot s^{i}}{\sum_{j=0}^{6} 2 b_{D j} \cdot s^{j}}
\end{aligned}
$$

gdzie współczynniki przy kolejnych potęgach zmiennej operatorowej s w liczniku i w mianowniku zapisano w postaci wektorów:

$$
\begin{aligned}
\mathbf{1 a}_{\mathbf{D}} \mathbf{1} & =\left[\begin{array}{lllll}
4,8 e 18 & 3,1 e 15 & 2,3 e 14 & 3,1 e 10 & 1,0 e 9
\end{array}\right] \\
\mathbf{1 a}_{\mathbf{D}} \mathbf{2} & =\left[\begin{array}{lllll}
1,4 e 18 & 3,5 e 14 & 4,2 e 13 & 4,1 e 9 & 2,0 e 8
\end{array}\right] \\
\mathbf{1} \mathbf{b}_{\mathbf{D}} & =\left[\begin{array}{llll}
4,4 e 21 & 2,7 e 19 & 2,5 e 18 & 1,3 e 15 \\
5,9 e 13 & 5,9 e 9 & 2,0 e 8
\end{array}\right] \\
\mathbf{2 a}_{\mathbf{D}} \mathbf{1} & =\left[\begin{array}{lllll}
4,8 e 18 & 3,8 e 15 & 2,3 e 14 & 3,6 e 10 & 1,0 e 9
\end{array}\right] \\
2 \mathbf{a}_{\mathbf{D}} \mathbf{2} & =\left[\begin{array}{lllll}
1,4 e 18 & 3,5 e 14 & 4,2 e 13 & 4,1 e 9 & 2,0 e 8
\end{array}\right] \\
\mathbf{2 b}_{\mathbf{D}} & =\left[\begin{array}{llll}
4,4 e 21 & 3,4 e 19 & 2,5 e 18 & 1,5 e 15
\end{array}\right.
\end{aligned}
$$

Bieguny transmitancji $1 p_{D i}, 2 p_{D i}$ wyznaczono jako pierwiastki wielomianu mianownika transmitancji, a zera transmitancji $1 z_{D} 1_{j}, 1 z_{D} 2_{j}, 2 z_{D} 1_{j}$ oraz $2 z_{D} 2_{j}$ jako pierwiastki wielomianu licznika transmitancji.

Wartości biegunów transmitancji układu zebrano w tabeli 9a, a wartości zer transmitancji zebrano w tabeli 9b.

Ze względu na to, że bieguny i zera transmitancji są liczbami zespolonymi, przypisuje się im fizyczną interpretację jako częstotliwości rezonansowe $1 \omega_{\text {Dir }}$, $2 \omega_{\text {Dir dla biegunów transmitancji oraz jako częstotliwości }}$ anty-rezonansowe $1 \omega_{\text {Djar }} 1,1 \omega_{\text {Djar }} 2,2 \omega_{\text {Djar }} 1$ i $2 \omega_{\text {Djar }} 2$ dla zer transmitancji.

Wartości częstotliwości rezonansowych układu zebrano w tabeli 10a, a częstotliwości anty-rezonansowych w tabeli $10 \mathrm{~b}$.
Wartości biegunów transmitancji układu

Tabela 9a

\begin{tabular}{|c|c|c|}
\hline \multirow{2}{*}{$i$} & \multicolumn{2}{|c|}{ Bieguny } \\
\cline { 2 - 3 } & $1 p_{D i}$ & $2 p_{D i}$ \\
\hline 1 & $-10,1 \pm \mathrm{j} \cdot 498,0$ & $-10,8 \pm \mathrm{j} \cdot 490,8$ \\
\hline 2 & $-4,4 \pm \mathrm{j} \cdot 225,0$ & $-4,7 \pm \mathrm{j} \cdot 225,0$ \\
\hline 3 & $-5,4 \pm \mathrm{j} \cdot 42,2$ & $-6,8 \pm \mathrm{j} \cdot 42,0$ \\
\hline
\end{tabular}

Wartości zer transmitancji układu

Tabela 9b

\begin{tabular}{|c|c|c|c|c|}
\hline \multirow{2}{*}{$j$} & \multicolumn{4}{|c|}{ Zera } \\
\cline { 2 - 5 } & $1 z_{D} 1_{j}$ & $1 z_{D} 2_{j}$ & $2 z_{D} 1_{j}$ & $2 z_{D} 2_{j}$ \\
\hline \multirow{2}{*}{1} & $-9,2$ & $-6,7$ & $-10,0$ & $-6,7$ \\
& $\pm \mathrm{j} \cdot 453,5$ & $\pm \mathrm{j} \cdot 413,3$ & $\pm \mathrm{j} \cdot 453,4$ & $\pm \mathrm{j} \cdot 413,3$ \\
\hline 2 & $-6,5$ & $-3,5$ & $-8,2$ & $-3,5$ \\
& $\pm \mathrm{j} \cdot 152,3$ & $\pm \mathrm{j} \cdot 203,3$ & $\pm \mathrm{j} \cdot 152,3$ & $\pm \mathrm{j} \cdot 203,3$ \\
\hline
\end{tabular}

Wartości częstotliwości rezonansowych

Tabela 10a

\begin{tabular}{|c|c|c|}
\hline \multirow{2}{*}{$i$} & \multicolumn{2}{|c|}{ Częstotliwości rezonansowe $[\mathrm{rad} / \mathrm{s}]$} \\
\cline { 2 - 3 } & $1 \omega_{\text {Dir }}$ & $2 \omega_{\text {Dir }}$ \\
\hline 1 & 499,0 & 499,0 \\
\hline 2 & 225,0 & 225,0 \\
\hline 3 & 42,6 & 42,6 \\
\hline
\end{tabular}

Wartości częstotliwości anty-

Tabela 10b rezonansowych

\begin{tabular}{|c|c|c|c|c|}
\hline \multirow{2}{*}{$\boldsymbol{j}$} & \multicolumn{5}{|c|}{ Czestotliwości anty-rezonansowe $[\mathrm{rad} / \mathrm{s}]$} \\
\cline { 2 - 5 } & $1 \omega_{\text {Djar }} 1$ & $1 \omega_{\text {Djar }} 2$ & $2 \omega_{\text {Djar }} 1$ & $2 \omega_{\text {Djar }} 2$ \\
\hline 1 & 453,6 & 413,4 & 453,5 & 413,4 \\
\hline 2 & 152,5 & 203,3 & 152,5 & 203,3 \\
\hline
\end{tabular}

Poglądową informację o charakterze zjawisk zachodzących w układzie uzyskuje się na podstawie analizy położenia biegunów i zer transmitancji na płaszczyźnie zespolonej. Rozkład zer i biegunów transmitancji badanego układu (współczynnik tłumienia $d_{2}=15\left[\frac{\mathrm{N} \cdot \mathrm{S}}{\mathrm{m}}\right]$ ), dla przypadku gdy wyjście i wejście układu związano $\mathrm{z}$ kierunkiem współrzędnej uogólnionej $q_{1}(t)$, przedstawiono na rysunku 8a, a gdy związano z kierunkiem współrzędnej uogólnionej $q_{2}(t)$ - na rysunku $8 \mathrm{~b}$.

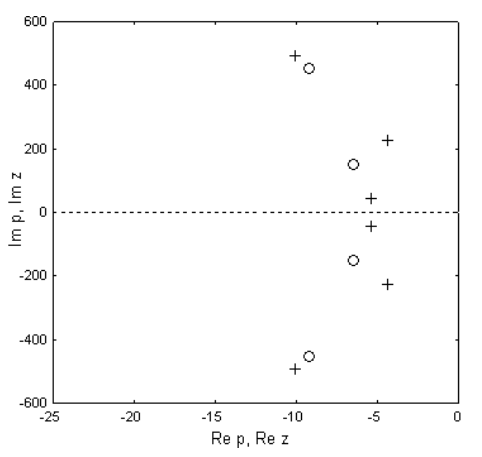

Rys. 8a. Położenie biegunów $2 p_{D i}(+)$ oraz zer $2 z_{D j} 1(\mathrm{O})$ transmitancji układu 


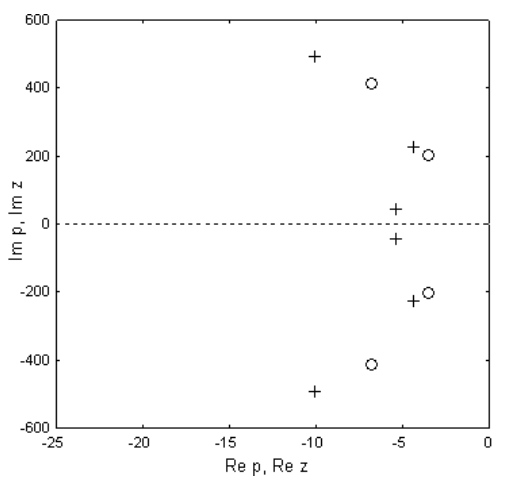

Rys. 8b. Położenie biegunów $2 p_{D i}(+)$ oraz zer $2 z_{D j} 2$ (O) transmitancji układu

W celu przedstawienia wpływu modyfikacji układu za pomocą elementu tłumieniowego na wartości częstotliwości rezonansowych i anty-rezonansowych przeprowadzono analizę częstotliwościową. Charakterystyki amplitudowoczęstotliwościowe (w skali decybelowej) wyznaczone dla badanych wariantów przedstawiono na: rys. 9a, rys. 9b, rys. $9 \mathrm{c}$ oraz rys. $9 \mathrm{~d}$.

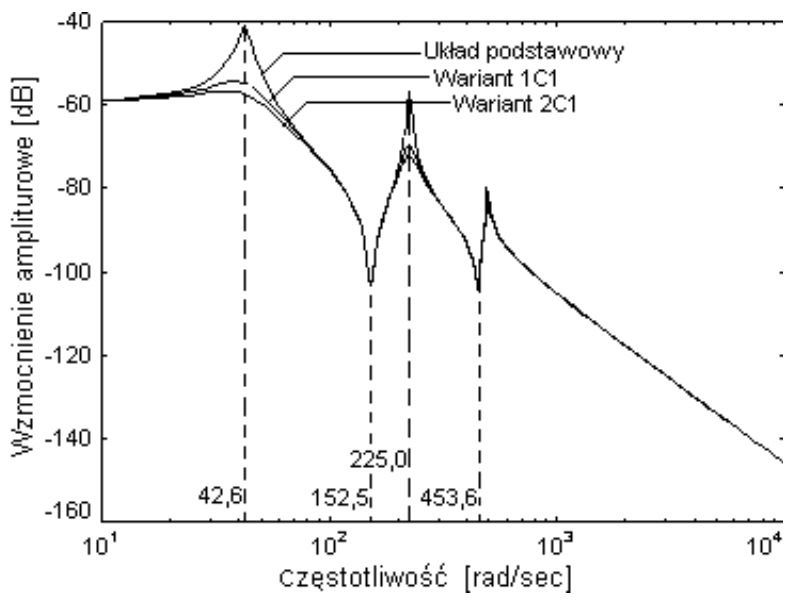

Rys. 9a. Decybelowe charakterystyki wzmocnienia dla układu podstawowego i wariantów $1 \mathrm{C} 1$ oraz $2 \mathrm{C} 1$ układu zmodyfikowanego

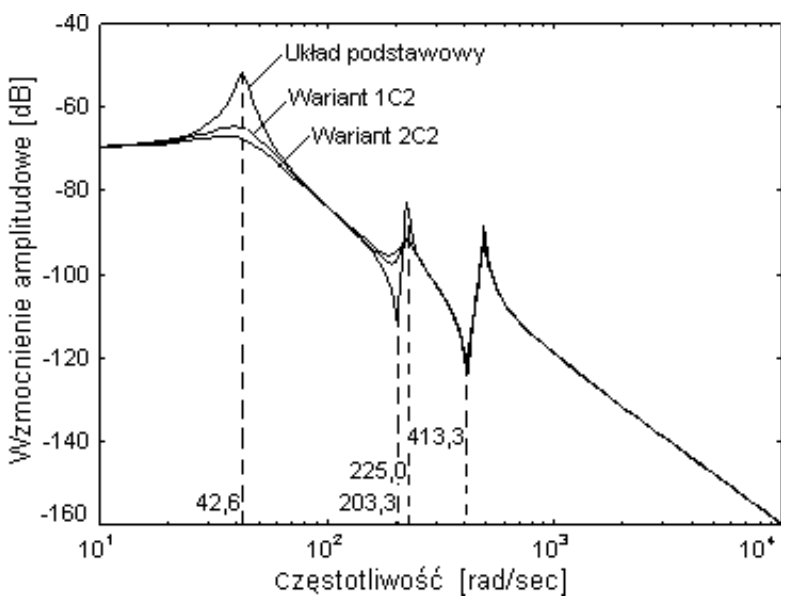

Rys. 9b. Decybelowe charakterystyki wzmocnienia dla układu podstawowego i wariantów $1 \mathrm{C} 2$ oraz $2 \mathrm{C} 2$ układu zmodyfikowanego

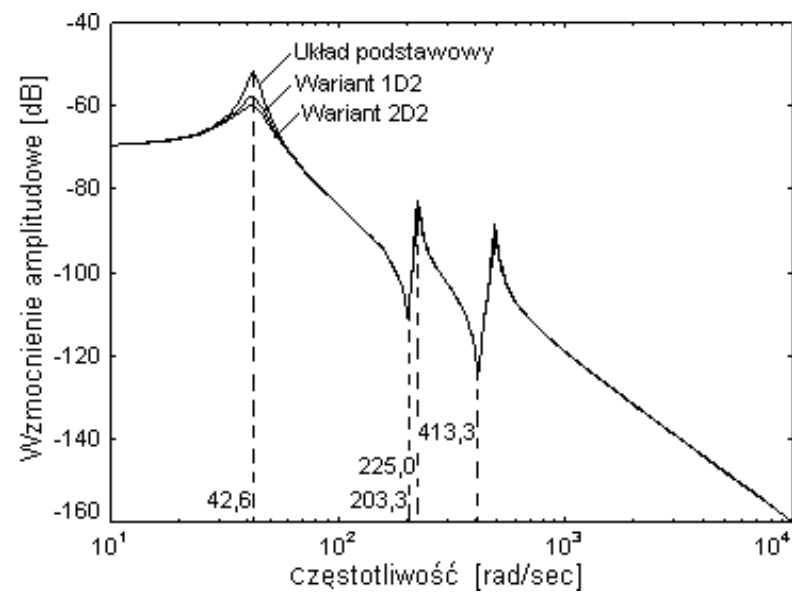

Rys. 9c. Decybelowe charakterystyki wzmocnienia dla układu podstawowego i wariantów 1D2 oraz 2D2 układu zmodyfikowanego

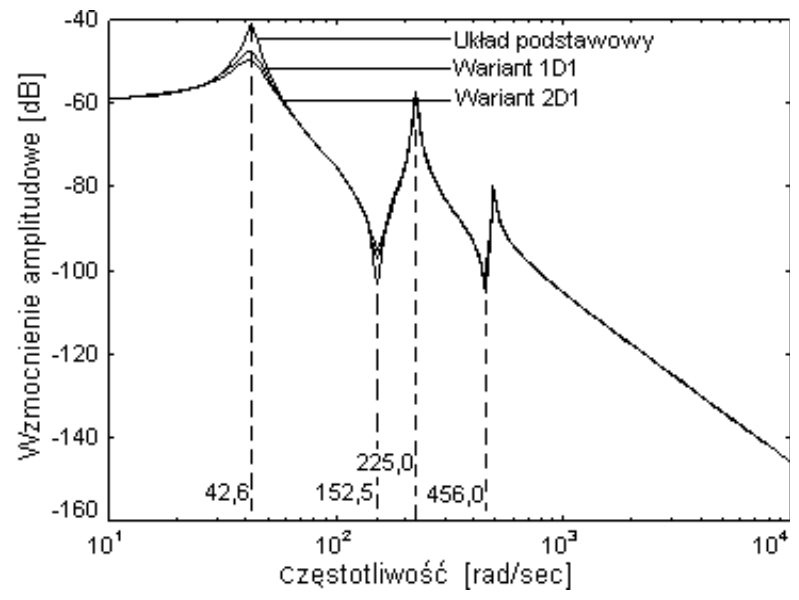

Rys. 9d. Decybelowe charakterystyki wzmocnienia dla układu podstawowego i wariantów 1D1 oraz 2D1 układu zmodyfikowanego

Modyfikacja układu za pomocą elementu tłumieniowego (tłumik wiskotyczny) powoduje zmiany położenia biegunów oraz zmiany położenia zer ale tylko w niewielkim stopniu zmienia wartości częstotliwości rezonansowych i anty-rezonansowych. Na wartości zer istotny wpływ ma postać wektora wejść i wektora wyjść.

Modyfikacja układu za pomocą elementu tłumieniowego powoduje, że nie jest spełniony warunek przemienności położenia zer i biegunów. Na podstawie rozkładu zer i biegunów możliwa jest zatem jakościowa ocena tłumienia w układzie.

$\mathrm{Na}$ podstawie analizy wyników stwierdzono, że wartości zer (wartości częstotliwości anty-rezonansowych) nie ulegają zmianie, jeśli modyfikacji podlega charakterystyka tłumieniowa układu na kierunku współrzędnej uogólnionej, na której działa wymuszenie oraz dokonywany jest pomiar. Wpływ lokalizacji elementu podpierającego belkę wspornikową na wartości częstotliwości rezonansowych i anty-rezonansowych jest najlepiej widoczny na wykresach charakterystyk częstotliwościowych. 


\section{Podsumowanie}

Analiza wyników przeprowadzonych badań numerycznych wskazuje na praktyczne aspekty wyznaczania zer i biegunów transmitancji w badaniach dynamiki liniowych układów mechanicznych. Stany dynamiki układu określane jako stan rezonansowy i stan anty-rezonansowy uzyskano poprzez modyfikację struktury układu (podpierając belkę wspornikowa - układ podstawowy - za pomocą liniowej sprężyny i liniowego tłumika), jak i za pomocą modyfikacji charakterystyk sztywnościowych i tłumieniowych zastosowanych elementów podparcia.

Bieguny transmitancji (częstotliwości rezonansowe) reprezentują układ ze względu na jego konstrukcję, natomiast zera transmitancji (częstotliwości anty-rezonansowe), reprezentują układ ze względu na jego konstrukcję oraz przyjęte schematy rozkładu wielkości wejściowych (kierunki wymuszeń) i wielkości wyjściowych (kierunki wielkości mierzonych). Zatem łączne badanie zer i biegunów transmitancji układu umożliwia ocenę jego dynamiki w aspekcie globalnym (bieguny) oraz lokalnym (zera), co niewątpliwie zwiększa możliwości i gwarantuje wyższą skuteczność prowadzonych badań w zakresie analizy dynamiki układów mechanicznych.

\section{Literatura}

[1] Barczak A., Wplyw thumienia wewnętrznego konstrukcji nośnej na charakterystyki dynamiczne układu z punktowym ttumikiem wiskotycznym. Zeszyty Naukowe Politechniki Poznańskiej, Maszyny Robocze i Transport, NR 56, Poznań 2003.

[2] Kaczorek T., Teoria sterowania i systemów, PWN, Warszawa 1993.

[3] Miu D. K., Physical Interpretation of Transfer Functions Zeros for Simple Control Systems With Mechanical Flexibilities, ASME Journal of Dynamic Systems, Measurements and Control, Vol. 113, Sept. 1991.

[4] Mottershead J. E., On The Zeros of Structural Frequency Response Functions and Their Sensitivities, Mechanical Systems and Signal Processing, Vol. 12, 1998.

[5] Mottershead J. E., Structural Modification for the Assignment of Zeros Using Measured Receptances, ASME Journal of Applied Mechanics, Vol. 68, 2001.

[6] MATLAB, wersja 5. 